\title{
The tale of springs and streams: How different aquatic ecosystems impacted the mtDNA population structure of two riffle beetles in the Western Carpathians
}

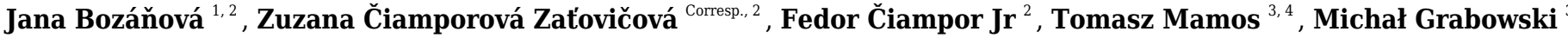 \\ ${ }^{1}$ Department of Ecology, Faculty of Natural Sciences, Comenius University in Bratislava, Bratislava, Slovak Republic \\ ${ }^{2}$ ZooLab, Plant Science and Biodiversity Centre, Slovak Academy of Sciences, Bratislava, Slovak Republic \\ 3 Department of Invertebrate Zoology and Hydrobiology, Faculty of Biology \& Environmental Protection, University of Lodz, Lodz, Poland \\ 4 Zoological Institute, University of Basel, Basel, Switzerland \\ Corresponding Author: Zuzana Čiamporová Zatovičová \\ Email address: zuzana.zatovicova@savba.sk
}

The Western Carpathians are a particularly interesting part of the Carpathian Arc.

According to recent molecular data upon aquatic and terrestrial taxa, this mountain area is an important biodiversity hotspot of Europe. Moreover, the W Carpathians include rich systems of karst springs inhabited by specific fauna, where molecular diversity and phylogeographic patterns are yet to be fully explored. Our study aims to compare population genetic structure and molecular diversity of two related and commonly cooccurring riffle beetles, Elmis aenea (PWJ Müller, 1806) and Limnius perrisi (Dufour, 1843) in the springs and streams of the W Carpathians using the mitochondrial DNA barcoding fragment of the cytochrome c oxidase subunit I gene (COI). The relatively stable thermal and chemical conditions of springs throughout unfavourable climatic settings make these highly specific lotic systems potentially ideal for a long-term survival of some aquatic biota. Populations of both elmid species were relatively homogeneous genetically, with a single dominant haplotype. However, we revealed that $E$. aenea significantly dominated in the springs, while $L$. perrisi preferred streams. Relative isolation of the springs and their stable conditions were reflected in significantly higher molecular diversity of the $E$. aenea population in comparison to L. perrisi. The results of Bayesian Skyline Plot analysis also indicated the exceptional position of springs regarding maintaining the population size of E. aenea. On the other hand, it seems that streams in the W Carpathians provide more effective dispersal channels for $L$. perrisi, whose population expanded much earlier compared to $E$. aenea. Present study points out that different demographic histories of these two closely related elmid species are manifested by their different habitat preference and molecular diversity. 
1 The tale of springs and streams: How different aquatic

2 ecosystems impacted the mtDNA population structure

3 of two riffle beetles in the Western Carpathians

4

5

6

7

8

Jana Bozáňová ${ }^{1,2}$, Zuzana Čiamporová-Zatovičová ${ }^{2}$, Fedor Čiampor $\mathrm{Jr}^{2}$, Tomasz Mamos ${ }^{3,4}$, Michal Grabowski ${ }^{3}$

${ }^{1}$ Department of Ecology, Faculty of Natural Sciences, Comenius University in Bratislava, Bratislava, Slovakia

${ }^{2}$ ZooLab, Plant Science and Biodiversity Centre, Slovak Academy of Sciences, Bratislava, Slovakia

${ }^{3}$ Department of Invertebrate Zoology and Hydrobiology, Faculty of Biology \& Environmental Protection, University of Lodz, Lodz, Poland

${ }^{4}$ Zoological Institute, University of Basel, Basel, Switzerland

Corresponding Author:

Zuzana Čiamporová-Zat'ovičová ${ }^{2}$

ZooLab, Dúbravská cesta 9, Bratislava, 845 23, Slovakia

Email address: zuzana.zatovicova@savba.sk

\section{Abstract}

The Western Carpathians are a particularly interesting part of the Carpathian Arc. According to recent molecular data upon aquatic and terrestrial taxa, this mountain area is an important biodiversity hotspot of Europe. Moreover, the W Carpathians include rich systems of karst springs inhabited by specific fauna, where molecular diversity and phylogeographic patterns are yet to be fully explored. Our study aims to compare population genetic structure and molecular diversity of two related and commonly co-occurring riffle beetles, Elmis aenea (PWJ Müller, 1806) and Limnius perrisi (Dufour, 1843) in the springs and streams of the W Carpathians using the mitochondrial DNA barcoding fragment of the cytochrome $\mathrm{c}$ oxidase subunit I gene (COI). The relatively stable thermal and chemical conditions of springs throughout unfavourable climatic settings make these highly specific lotic systems potentially ideal for a long-term survival of some aquatic biota. Populations of both elmid species were relatively homogeneous genetically, with a single dominant haplotype. However, we revealed that $E$. aenea significantly dominated in the springs, while L. perrisi preferred streams. Relative isolation of the springs and their stable conditions were reflected in significantly higher molecular diversity of the $E$. aenea population in comparison to L. perrisi. The results of Bayesian Skyline Plot analysis also indicated the exceptional position of springs regarding maintaining the population size of $E$. aenea. On the other hand, it seems that streams in the $\mathrm{W}$ Carpathians provide more effective dispersal channels for $L$. perrisi, whose population expanded much earlier compared to E. aenea. Present study points out that different demographic histories of these two closely related elmid species are manifested by their different habitat preference and molecular diversity. 


\section{Introduction}

44 Prolonged isolation of populations influences their genetic diversity and can be considered as the 45 main force shaping genetic structure of aquatic species in Europe (Bálint et al., 2011; Alp et al., 46 2012; Theissinger et al., 2012). Many mountain areas have often formed isolated populations of 47 aquatic invertebrates within and/or among geomorphological units/subunits (Engelhardt, Haase 48 \& Pauls, 2011; Davis et al., 2013; Mamos et al., 2016; Čiamporová-Zat'ovičová \& Čiampor Jr, 49 2017; Š́pošová, Čiamporová-Zat’ovičová \& Čiampor Jr, 2017; Copilaș-Ciocianu et al., 2018).

50 The W Carpathians are considered a biodiversity hotspot for a wide range of aquatic and 51 terrestrial taxa (Neumann et al., 2005; Kotlík et al., 2006; Theissinger et al., 2012; Vörös et al., 2016; Copilaș-Ciocianu et al., 2017; Juřičková et al., 2017). However, the biodiversity of the W Carpathians is still underexplored, especially in terms of genetic diversity and population structure of aquatic species. In this context, studies upon the phylogeography of aquatic biota should be more focused on springs, or more generally, headwaters that are now heavily understudied compared to other aquatic biotopes.

Springs support unique macroinvertebrate communities that are found nowhere else in a catchment (Lewin et al., 2015). They are characterized by chemical, physical, and trophic constancy over several geological periods (Minshall \& Winger, 1968; Odum, 1971; Butler \& Hobbs, 1982; Cushing \& Wolf, 1984; Glazier \& Gooch, 1987; Pringle et al., 1988; Gooch \& Glazier, 1991; Orendt, 2000; Wood et al., 2005; Meyer et al., 2007), which in turn provided a stable environment for aquatic invertebrates during adverse climatic conditions (Malicky, 2006; Ujvárosi et al., 2010). Springs function as ecotones between the surface and underground waters, which makes them an ecologically significant habitat (Gibert, 1991).

Accordingly, the main objective of our study is to compare genetic population structure and diversity patterns of two aquatic beetle species of Elmidae family, Elmis aenea (PWJ Müller, 1806) and Limnius perrisi (Dufour, 1843) in springs and streams of the W Carpathians. Said species are relatively closely related and commonly co-occur, yet in terms of population genetics represent a generally understudied family of freshwater beetles. Limited dispersal abilities, high habitat specificity, and more or less fragmented distribution make Elmidae an ideal taxon for studying genetic diversification through many geographic regions. Both studied species are rheophilic, oligo-stenotherm, and typical inhabitants of epirhithral streams at higher altitudes (Moog \& Jäch, 1995; García-Criado, Fernández-Aláez \& Fernández-Aláez, 1999). They are relatively widespread, which guarantees the detection of possible gene flow among geomorphological units/subunits of W Carpathians.

Our study aims to answer the following questions: (a) are the spring subpopulations genetically more variable when compared to subpopulations in the streams?; (b) does genetic structuring of populations reflect population size change?; and (c) are there interspecific differences in the population genetic structure among these related beetle species?

\section{Materials \& Methods}

\section{Study area}

The Carpathians form an arc of mountains stretching across Central and Eastern Europe, with its main geomorphological units being the Western and Southeastern Carpathians (Kondracki, 1989). For this study, we focused on the W Carpathians representing the northernmost segment of the Alpine-Carpathian mountain chain (Fig. 1A). The W Carpathians reach medium altitudes 
87 (ranging from 500 to $1300 \mathrm{~m}$ a.s.1.), only a few of their ranges exceed $1500 \mathrm{~m}$ a.s.l.; geologically 88 the mountain system is characteristic by interactions of rock folding and horizontal shifts (Bielik, 89 1999). Differences in altitude and in the geomorphological relief determine the precipitation in 90 the area. In general, W Carpathian rivers have a rain-snow regime with floods in spring and 91 summer.

92 Investigated localities (36 springs and 37 streams) are situated mainly on the territory of the 93 Slovak Republic, partially in the Czech Republic and Poland; in the geomorphological 94 units/subunits of the Inner and Outer Western Carpathians. The exceptions are Vihorlat Mts 95 (VM) being part of the Inner Eastern Carpathians and Poloniny Mts (PM) belonging to the Outer 96 97 Eastern Carpathians (Fig. 1B, Table S1).

\section{Sampling and morphological identification}

A qualitative sampling of benthic invertebrates took place in 2016 and 2017. The sampling was performed in the framework of a broader research, which was permitted by The District Office, Department of Environmental Care Trenčín (Slovakia) No: OU-TN-OSZP1-2015/001937-12/Du. A sampling of macrozoobenthos was carried out by a multi-habitat kick-sampling technique (Frost, 1971) using a hydrobiological hand-net with a mesh size of $0.5 \mathrm{~mm}$. Organic material was fixed in $96 \%$ ethanol directly in the field. In the laboratory, the invertebrates were picked off, sorted into higher taxonomic groups using stereomicroscope, prefixed with absolute ethanol and stored in a freezer at $-25^{\circ} \mathrm{C}$. Elmidae beetles selected for molecular analysis were morphologically identified using the available determination keys (Więźlak, 1986; Jäch, 1992).

\section{DNA extraction and PCR amplification}

Total DNA was extracted from the legs or abdominal tissue of 560 individuals (297 individuals of E. aenea; 263 individuals of L. perrisi) using the Chelex protocol (Casquet, Thebaud \& Gillespie, 2012), followed by PCR amplification of ca. 650 bp-long barcoding fragment of the mitochondrial cytochrome c oxidase subunit I (COI) using the primer pair LCO1490 and HCO2198 (Folmer et al., 1994). The PCR was performed in a total volume of $25 \mu$ l containing 5 $\mu 1$ of $5 x$ DreamTaq ${ }^{\mathrm{TM}}$ Buffer, $1.5 \mu \mathrm{l}$ of $\mathrm{Mg}^{+2}(25 \mathrm{mM}), 0.5 \mu \mathrm{l}$ of each primer (concentration 5 $\mathrm{mM}), 0.5 \mu \mathrm{l}$ of dNTP Mix $(20 \mathrm{mM}), 0.125 \mu \mathrm{l}(0.625 \mathrm{U})$ DreamTaq ${ }^{\mathrm{TM} D N A}$ Polymerase, 11.875 $\mu \mathrm{l}$ ultra-pure $\mathrm{H}_{2} \mathrm{O}$ and $5 \mu \mathrm{l}$ of DNA template. The PCR cycling consisted of a 2-min initial denaturation at $94{ }^{\circ} \mathrm{C}$, followed by 40 cycles of $94{ }^{\circ} \mathrm{C}(40 \mathrm{~s})$ denaturation, $46^{\circ} \mathrm{C}(40 \mathrm{~s})$ annealing and $72{ }^{\circ} \mathrm{C}(1 \mathrm{~min})$ extension and termination at $72{ }^{\circ} \mathrm{C}(10 \mathrm{~min})$ for a final extension. A $4 \mu \mathrm{l}$ aliquot of the PCR products were visualized by GoldView (Solarbio) in electrophoresis on a $1 \%$ agarose gel and GelLogic imaging equipment to check PCR product quality and length. The PCR products were purified with Exo-FastAP Thermo Scientific and were sent for sequencing to Macrogen Europe Inc., Amsterdam.

\section{Data analyses}

To determine whether the different habitat preference (springs, streams) between the studied species is statistically significant, we used Fisher's exact tests using the fisher.test function in R v 4.0.2 (http://www.r-project.org). It was performed for testing the independence of rows (species: E. aenea, L. perrisi) and columns (springs, streams) in a $2 \times 2$ contingency table. Odds ratio and p-value were computed. P-values $<0.05$ were considered statistically significant. We used analysis of variance (ANOVA) to test significance of the influence of altitude on the presence of species in different habitats (springs, streams). ANOVA test was performed in $\mathrm{R} v$ 4.0.2 
133 (http://www.r-project.org). All R analysis were carried out using RStudio (RStudio Team. 2020).

134 The altitude range of E. aenea and L. perrisi is shown with boxplots.

135 The obtained sequences were edited using SEQUENCHER v5.1 software and aligned using the 136 MUSCLE algorithm (Edgar, 2004) in MEGA v7 (Kumar, Stecher \& Tamura, 2016). In total, our 137 study included 315 sequences of E. aenea species, of which 276 were from the Western 138 Carpathians and 269 sequences of L. perrisi, of which 245 were from the Western Carpathians. 139 We used 39 sequences of E. aenea (12 - Romania, 9 - Bulgaria, 15 - Germany, 2 - Finland, 1 140 France) and 24 of L. perrisi (16 - Romania, 2 - Bulgaria, 6 - Germany) outside of W Carpathians

141

142

143

144

145

146

147

148

149

150

151

152

153

154

155

156

157

158

159

160

161

162

163

164

165

166

167

168

169

170

171

172

173

174

175

176

177 for haplotype networks. Sequences from Germany, Finland and France were downloaded from BOLD (www.boldsystems.org) and are included in datasets DS-SKLIMPER (DOI: dx.doi.org/10.5883/DS-SKLIMPER), DS-SKELMAEN (DOI: dx.doi.org/10.5883/ DSSKELMAEN). For the purposes of the paper, individuals (sequences) from each locality of $\mathrm{W}$ Carpathians are defined as subpopulation regardless of whether the locality is a spring or stream (Table S1).

The haplotype data files and the diversity indices were generated in DnaSP v5.10 (Librado \& Rozas, 2009). We also calculated haplotype diversity $(\mathrm{H})$, nucleotide diversity $(\pi)$, number of polymorphic sites (S) and average number of nucleotide differences (K) per subpopulation of both species using DnaSP v5.10. Subsequently, a statistical comparison of molecular genetic indices between species, based on p-values, was computed with the Wilcoxon signed rank test for paired data in R v 4.0.2 (http://www.r-project.org). The results are presented by boxplots with p-values.

Haplotype networks were reconstructed using the median-joining method (MJN) in PopART v1.7 (Leigh \& Bryant, 2015). The networks include some sequences outside the W Carpathians to explain the phylogenetic relationships and haplotype distribution of E. aenea and L. perrisi in the broader context of the investigated localities.

The population structure of both species was characterized by the analysis of molecular variance (AMOVA) and fixation indices $\left(\mathrm{F}_{\mathrm{sT}}\right)$ using Arlequin 3.5 (Excoffier \& Lischer, 2010). The AMOVA was used to estimate whether the observed genetic diversity may be attributed to the geographical partitioning of elmid beetle populations in three levels: among geomorphological subunits, among subpopulations within subunits and within subpopulations. For the consistency of the study, we also performed AMOVA for both species based on the partitioning of the data according to river basins. The results and map showing the river basins are included in the supplementary materials.

$\mathrm{F}_{\mathrm{st}}$ index is a measure of the genetic differentiation among subpopulations of individual localities by haplotype frequencies. $265 \mathrm{E}$. aenea sequences (42 localities - 29 springs, 13 streams) and 136 L. perrisi sequences ( 36 localities - 5 springs, 31 streams) were included to calculate the $\mathrm{F}_{\mathrm{sT}}$ index. Localities with 1 sequence were excluded from the calculation. To test the significance of covariance components and fixation indices, 1000 permutations were performed.

To test if spatial distance is structuring the molecular diversity we run two types of isolation by distance tests: Mantel test (Mantel, 1967) and general spatial autocorrelation test (see Miller, 2005) using the program Alleles in Space (Miller, 2005). Both tests analyse correlation between spatial and molecular distance, to assess the significance tests were run with 1000 permutations. Further, the demographic and spatial dynamics of studied beetle populations were examined by the mismatch distribution analysis in Arlequin v3.5. The recent demographic expansion in both species was tested with Tajima's D (Tajima, 1989), Fu's Fs (Fu, 1997) and Fu and Li's D (Fu \& 
$178 \mathrm{Li}, 1993)$ tests of selective neutrality and population stability, performed in DnaSP. The 179 significance of these tests was assessed with 10000 permutations.

180 The fluctuations of demography of E. aenea and L. perrisi in the W Carpathians over time were identified with the extended Bayesian Skyline Plot (eBSP) in BEAST v2.6.2 software package (Bouckaert et al., 2019). The strict molecular clock was calibrated with the standard mitochondrial rate for arthropod COI equal to 0.0115 substitutions/site/Myr (Brower, 1994). The models of molecular evolution were set up through bModelTest (Bouckaert \& Drummond, 2017). For comparison, two runs of Monte Carlo Markov Chains (MCMC) were performed for each species, each 40 million iterations long and sampled every 10000 iterations for eBSP log. The runs were examined in Tracer v1.7 (Rambaut et al., 2018) and all the parameters reached the effective sampling size (ESS) above 200. After removal of $10 \%$ burn-in, the eBSP plots were produced using R v 4.0.2 software (http://www.r-project.org). Both plots for each species were identical therefore only one is presented.

All analysed sequences with GenBank accession numbers are available within two BOLD datasets: DS-SKLIMPER for L. perrisi (DOI: dx.doi.org/10.5883/DS-SKLIMPER) and DSSKELMAEN for E. aenea (DOI: dx.doi.org/10.5883/DS-SKELMAEN).

194

195

\section{Results}

196

197

198

199

200

201

202

203

204

205

206

207

208

209

210

211

212

213

214

215

216

217

218

219

220

221

222

223
The distribution of $E$. aenea and $L$. perrisi suggests statistically significant different habitat preferences between these species in the W Carpathians ( $<<0.0001$; Fisher's exact test). E. aenea has a rather wide distribution in karst springs (31 sites), while it is less widespread in streams (16 sites). On the contrary, L. perrisi was found only in eight springs, but in 30 streams. L. perrisi was also found in four streams of VM (Inner Eastern Carpathians) and in one stream of PM (Outer Eastern Carpathians), while E. aenea was not recorded in these geomorphological subunits. Both species co-occurred only in three springs and 14 streams from the total of 73 sites sampled in the W Carpathians (Table S1). There was also a significant effect of altitude on the presence of both species registered, but the dependence between altitude and habitat type (spring and stream) has not been demonstrated. The altitude range of both elmid species is shown by boxplots in Fig. 1C.

The haplotype distribution within investigated area shows that local subpopulations of the two elmid species are dominated, each by one widespread haplotype (Figs 2A, 3A). Haplotype networks (Figs 2B, 3B) also showed the similar haplotype pattern i.e., star-like topology with a central most-frequent haplotype. However, statistical comparisons of molecular genetic indices: haplotype diversity $(\mathrm{H})$, nucleotide diversity $(\pi)$, number of polymorphic sites $(\mathrm{S})$, and average number of nucleotide differences $(\mathrm{K})$ showed significant differences between the studied species. The population of $E$. aenea was significantly more diverse than $L$. perrisi $(\mathrm{P}<0.05$, Wilcoxon signed-rank test, Fig. 4).

The W Carpathian population of E. aenea shares haplotypes with locations in Romania, Bulgaria, Finland, Germany and France. 13 COI haplotypes of E. aenea were identified within 276 individuals collected from 47 localities in the W Carpathians (Fig. 2A). The haplotype diversity was 0.336 . Considerable genetic homogeneity of the E. aenea population in the $\mathrm{W}$ Carpathians resulted from the wide distribution of the dominant haplotype Ea1. The haplotype map (Fig. 2B) revealed that the majority of haplotypes present in southern part of the Carpathians Arc (Romania) and the haplotypes of the Balkan region (Bulgaria) were not recorded from the $\mathrm{W}$ Carpathians. The exception was Ea14 shared between one stream in Bulgaria and one spring (V050) in Slovakia (SOM). Individuals from Germany shared the 
224 haplotype Ea3 with a single locality in the geomorphological unit FTA (V070). In addition to 225 dominant haplotype Ea1, another five haplotypes were found in FTA and seven in SOM. 226 Haplotypes Ea5 and Ea11 were private for W Carpathians and each occurred in one spring of 227 FTA (V009, V086). The private haplotypes of SOM included Ea7, Ea12 and Ea13, while all of 228 them were located in the springs of SOM1 subunit (V038, V048). Besides that, one spring of 229 SOM1 (V043) shared haplotype Ea8 with the spring of the geomorphological unit FTA (V020). 230 In geomorphological unit WB, four haplotypes were found, while Ea9 was found only at two 231 localities (CZ03, CZ05). On the contrary, the haplotype Ea4 was common in the SOM, FTA, CB 232 and in Romania (Figs 2A, 2B).

233 The W Carpathians population of $L$. perrisi was genetically more homogeneous. Eight 234 haplotypes with a haplotype diversity of 0.007 were found at 43 localities $(245$ sequences, Fig. 235 3A). A group of five haplotypes (Lp5, Lp6, Lp7, Lp8, Lp9) recorded in Romania and Bulgaria 236 was highly divergent from the group found in the W Carpathians (Fig. 3B). Haplotype Lp1 237 dominated in all geomorphological units of the W Carpathians; all German sequences also 238 belonged to this haplotype. The presence of private haplotypes was lower compared to E. aenea: Lp14 from the one spring of SOM (V088), Lp10 in a stream of WB (CZ06) and Lp11 from one spring of geomorphological unit FTA (V070). Besides that, two more haplotypes (Lp3, Lp13) were present in the FTA. Lp13 was shared with the locality of the different geomorphological unit SMC (SEL1). Lp3 was also present in unit WB, in addition to FTA (BEL3). The haplotype Lp2 was detected in a stream (CZ01) of WB and occurred also in one stream (KRV1) located in VM (Figs 3A, 3B).

The AMOVA showed that most of the observed molecular variance in the $\mathrm{W}$ Carpathian populations of both elmid species is generated predominantly within subpopulations (single localities). However, in E. aenea, the molecular variation among subpopulations within geomorphological subunits is more than twice (34.99\%) compared to L. perrisi $(12.86 \%)$ (Table 1). The same results were provided by the AMOVA according to the river basins, where there is also almost no variation associated with the above subpopulation (locality) level (Fig. S1, Table S2).

The $\mathrm{F}_{\mathrm{sт}}$ values indicate different levels of genetic differentiation between the $E$. aenea localities 0

253

254 - 0.8(Fig. 5A) compared to L. perrisi with 0 - 0.38 (Fig. 5B). The $\mathrm{F}_{\mathrm{s \tau}}$ values of E. aenea suggest that springs V009 (FTA1 - Little Carpathians), V038, and V048 (SOM1 - Slovak Karst) have 255 256 relatively high pairwise differences in allele frequency, but some level of genetic connectivity cannot be refused. Pairwise comparisons of differences in the frequency of alleles that include mentioned springs are largely significant $(\mathrm{P}<0.05)$. On the other hand, none of L. perrisi $\mathrm{F}_{\mathrm{st}}$ values are statistically significant.

Tests of isolation by distance between springs of both species revealed a positive correlation (Mantel test: E. aenea $-\mathrm{r}=0.313, \mathrm{P}=0.000 ;$ L. perrisi $-\mathrm{r}=0.4122, \mathrm{P}=0.039$ ). Although, only marginally positive but statistically significant correlations suggest a slight structuring effect of the geographical distance among springs in both species. Additionally in case of E. aenea, the

263

264

265

266

267 spatial autocorrelation was also significant $(\mathrm{P}=0.0009$, Fig. S2), for $L$. perrisi it was impossible to calculate it due to lack of data. The genetic distance of $E$. aenea and L. perrisi in streams was not significantly correlated with the geographic distance (Mantel test: $\mathrm{r}=-0.071, \mathrm{P}=0.153 ; \mathrm{r}=$ $0.0574, \mathrm{P}=0.115)$.

Both species were characterized by the statistically significant, negative Fu's Fs, Tajima's D and 269 $\mathrm{Fu}$ and Li's D neutrality test values (Table 2). This indicates a recent change in population size of both species. The mismatch distribution analysis suggested a population expansion event for 
270 both species, which was indicated by the unimodal shape of the mismatch distribution plot, a 271 small SSD value, and a non-significant p-value (Fig. 6). The eBSP showed a signal of population 272 growth in both species, although the time and character was different. The W Carpathians 273 population of E. aenea (Fig. 7A) started to expand demographically roughly ca. 3000 - 2500 274 years ago, whereas the population of $L$. perrisi expanded relatively sharply around 8000 years 275 ago (Fig. 7B).

276

\section{Discussion}

278 This study was focused on the two oligo-stenotherm riffle beetles, Elmis aenea and Limnius 279 perrisi (Elmidae). The $E$. aenea occurred predominantly in karst springs and was rarely found in 280 streams of the W Carpathians, while the distributional pattern of L. perrisi was opposite. This 281 contradicts the previous claims about their common occurrence and similar biotope preference 282 (Moog \& Jäch, 1995; García-Criado, Fernández-Aláez \& Fernández-Aláez, 1999). Differences in 283 distribution probably can be also explained by altitude, flow type or different ecological demands 284 (Illies \& Botosaneanu, 1963). However, according to several studies, E. aenea is more sensitive to harsher conditions resulting from changes of the aquatic environment, manifested, for example, by the loss of macrophytes and moss (Maitland, 1967; Bradley \& Ormerod, 2001; Hoffsten, 2003). These findings may explain much greater affinity of $E$. aenea to springs that generally, with respect to chemical, physical and trophic conditions, are more stable ecosystems compared to other lotic habitats (Minshall \& Winger, 1968; Odum, 1971; Butler \& Hobbs, 1982; Cushing \& Wolf, 1984; Glazier \& Gooch, 1987; Gooch \& Glazier, 1991). This suggests that karst springs ensured a suitable environment for survival of some aquatic species even during the ice age (Thorup \& Lindegaard, 1977). It supports the dinodal hypothesis (Malicky, 1983; Malicky, 2000) proposing that suitable aquatic habitats, persisted throughout the Pleistocene within the periglacial area (dinodal biome), providing suitable conditions for the survival of specialized oligo-stenotherm communities in Central Europe. However, based on our data from the W Carpathians only, the dinodal hypothesis cannot be unequivocally confirmed or refuted, but it clearly opens up new questions in the field of historical-molecular patterns of elmid species in the W Carpathians.

Different results of the Bayesian Skyline Plot analyses between E. aenea and L. perrisi confirmed an exceptional position of the springs. The springs could have a special status in terms of providing stable environmental conditions irrespective of the climatic changes even during the glacial and interglacial periods which did not provoke a dramatic decline or increase of the $E$. aenea population size in the $\mathrm{W}$ Carpathians. In contrast, the populations of $L$. perrisi, occurring predominantly in streams, began to expand rapidly after the LGP. At the beginning of the Holocene (about $11.5-7.5 \mathrm{ka}$ ), a thermal maximum was recorded, which probably enhanced the expansion of species (Dabkowski et al., 2019), which corresponds to sudden expansion of $L$. perrisi. At that time, local W Carpathian glaciers disappeared completely (Lindner et al., 2003), which led to opening of new migration routes and likely also accelerated species dispersal. Early-Holocene warming is thought to be a major driving force for population divergence in temperate species (Hewitt, 1999). On the other hand, differences in genetic diversity among species, as recorded between E. aenea and L. perrisi may be also influenced by variation in diversification rates (Ricklefs, 2007; Stadler, 2011).

The E. aenea population has occurred in springs at a significantly higher rate, corresponding to its higher molecular diversity compared to L. perrisi that prefers streams and its populations are much more uniform. In line with our results, populations of two cofamilial caddisfly species in 
316

317

318

319

320

321

322

323

324

325

326

327

328

329

330

331

332

333

334

335

336

337

338

339

340

341

342

343

344

345

346

347

348

349

350

351

352

353

354

355

356

357

358

359

360

south-eastern UK showed contrasting genetic patterns. Polycentropus flavomaculatus showed much more pronounced genetic structure than Plectrocnemia conspersa in the same region (Wilcock et al., 2007). In another study on caddisflies of the Central European highlands, Drusus discolor contained three times more haplotypes than Hydropsyche tenuis. Such findings suggest that the isolation of $D$. discolor populations in Central Europe is stronger and persists for a longer time than in H. tenuis (Lehrian, Pauls \& Hasse, 2009). Both cases, similarly with species studied herein, confirm that related and co-occurring species may currently have significantly different patterns of molecular diversity, reflecting the different phylogeographical histories of the species and their different autecological traits (Wilcock et al., 2007; Lehrian, Pauls \& Haase, 2009).

Compared to aquatic species occurring in streams, the species preferring springs are generally unable to spread extensively and likely persisted at the foothills of mountains during unfavorable climatic conditions (Schmitt, 2007). As a consequence, many of the geomorphological units of the European mountain systems have their own genetic lineages or at least private haplotypes. In our study, we recorded significantly higher values of molecular diversity and higher number of private haplotypes in E. aenea. In addition, analysis of spatial autocorrelation for E. aenea in springs was significant and consistent with these results. This suggests subpopulations in springs persisted in the study area for a longer time, and are relatively isolated. Conversely, stream subpopulations are more homogeneous and smaller, suggesting that they are probably more recent and are being re-created when environmental conditions improve. Valuable examples documenting the importance of the $\mathrm{W}$ Carpathians in terms of biodiversity richness were recent discoveries of local endemism of cold-adapted gammarids from Gammarus balcanicus (Mamos et al 2014; Mamos et al., 2016) and Gammarus fossarum species complexes (Copilaș-Ciocianu et al., 2017) or caddisfly species Drusus discolor. The latter persisted in the Tatra Mts in numerous refugia over multiple glacial cycles, allowing many local endemic clades to form (Pauls, Lumbsch \& Haase, 2006). In the case of E. aenea, the two localities in the Slovak Ore Mts (SOM: V038, V048) and one locality in the Fatra-Tatra area (FTA: V009) had remarkably high $\mathrm{F}_{\mathrm{ST}}$ values, suggesting that some $\mathrm{W}$ Carpathian springs could constitute Pleistocene refugia. According to several studies, the role of the W Carpathians as a glacial refugium (Jamřichová, Potůčková \& Horsák, 2014; Mráz \& Ronikier, 2016; Jamřichová, Petr \& Jiménez-Alfaro, 2017) for various species or genetic lineages is undoubted (Pinceel et al., 2005; Magri et al., 2006; Wielstra, Babik \& Arntzen, 2015; Mamos et al., 2016; Copilaș-Ciocianu et al., 2017). However, to test whether this hypothesis also applies to Elmidae riffle beetles requires further study in a broader geographical context.

Overall, the genetic differences between populations from different geomorphological subunits of the W Carpathians were very low in both elmid species. However, higher $\mathrm{F}_{\mathrm{sT}}$ values in $E$. aenea correlated with the results of AMOVA. Genetic differentiation among E. aenea subpopulations within geomorphological subunits was relatively high (34.99\%). This indicates that there are some well pronounced differences in genetic composition among most of the spring subpopulations of $E$. aenea within each geographical unit. Similar results emerged from the study on the black fly Prosimulium neomacropyga in the US Southern Rockies ecoregion with alpine tundra streams, where the differences among streams within the region were $24.58 \%$ (Finn et al., 2006). In both elmid species, only a single haplotype was abundant and widespread along the W Carpathians, surrounded by several rare peripheral haplotypes in a star-shaped topology. Similarly, lack of deeper genetic population structure was also found in the W 
361 Carpathian populations of the blackfly Simulium degrangei (Jedlička et al., 2012). The

362

363

364

365

366

367

368

369

370

371

372

373

374

375

376

377

378

379

380

381

382

383

384

385

386

387

388

389

390

391

392

393

394

395

396

397

398

399

400

401

402

403 maintenance of intraspecific genetic diversity is generally very important for the adaptation potential and long-term survival of species (Spielman, Brook \& Frankham, 2004; Frankham, 2005). However, prolonged persistence is possible even despite low levels of genetic diversity (Johnson et al., 2009). Relatively homogeneous population patterns of both studied riffle beetles may reflect their short history in the $\mathrm{W}$ Carpathians. The comparatively low genetic differentiation among populations of trickle midges (Diptera: Thaumaleidae) in Northern Europe was also explained by relatively recent, possibly post-glacial dispersal (Haubrock et al., 2017).

\section{Conclusions}

In conclusion, it seems that different habitat preferences of the two related aquatic beetle species E. aenea and $L$. perrisi preserved their similar population-geographical patterns, but shifted their molecular diversity, as well as the time and character of their distribution in the W Carpathians. E. aenea, with higher molecular diversity, occurred mainly in the springs compared to the genetically more homogenous population of $L$. perrisi that was found mostly in streams. These findings support the attribution of the $\mathrm{W}$ Carpathian springs to potential refugia with a suitable environment allowing for survival of aquatic biota even during the unfavorable climatic conditions through geological ages and maintaining or even developing its intraspecific genetic diversity. In addition, an isolation of the $\mathrm{W}$ Carpathians springs is also indicated by the significant results of Mantel and spatial autocorrelation analysis in E. aenea. This study added new information about understudied riffle beetle fauna of one of the world's biodiversity hotspots, the W Carpathians. However, further studies should include more samples from Southern and Eastern Europe in order to understand the holistic biogeographic pattern of the target species and spring fauna in general.

\section{Acknowledgements}

We would like to thank Darina Arendt for help with laboratory work, Maroš Kubala for his help in the statistical data processing and the working team of the Department of Ecology, Comenius University in Bratislava, who performed fieldwork with us. Thanks also go to the Erasmus+ program within which Jana Bozáňová carried out part of the research in the laboratory of the Department of Invertebrate Zoology and Hydrobiology of the University of Łódž. This study was supported by the Slovak National Grant Agency VEGA 2/0030/17, VEGA 1/0127/20 and Miniatura 2017/01/X/NZ8/01607 (Polish NCN) as well as by the statutory funds of the University of Lodz. The fieldwork for this study was financed by the grant SK-PL-2015-0042 "Cryptic refugia and diversification patterns of aquatic invertebrates in the Western Carpathians" within the Slovak-Polish bilateral projects 2016-2017. Tomasz Mamos was supported by the Scholarship of the Polish National Agency for Academic Exchange (NAWA) at Bekker Programme (project nb. PPN/BEK/2018/1/00225).

\section{References}

Alp M, Keller I, Westram AM, Robinson CT. 2012. How river structure and biological traits influence gene flow: a population genetic study of two stream invertebrates with differing dispersal abilities. Freshwater Biology 57:969-981.

Peer) reviewing PDF | (2020:05:49199:2:1:NEW 3 Sep 2020) 
404 Bálint M, Domisch S, Engelhardt CHM, Haase P, Lehrian S, Sauer J, Theissinger K, Pauls SU, 405 Nowak C. 2011. Cryptic biodiversity loss linked to global climate change. Nature climate change 406 1:313-318.

407 Bielik M. 1999. Geophysical features of the Slovak Western Carpathians. Geological Quarterly 408 43:251-262.

409 Bouckaert RR, Drummond AJ. 2017. bModelTest: Bayesian phyloge-netic site model averaging 410 and model comparison. BMC Evolutionary Biology 17(1): 42.

411 Bouckaert R, Vaughan TG, Barido-Sottani J, Duchêne S, Fourment M, Gavryushkina A, Heled J, 412 Jones G, Kühnert D, De Maio N, Matschiner M, Mendes FK, Müller NF, Ogilvie HA, du Plessis 413 L, Popinga A, Rambaut A, Rasmussen D, Siveroni I, Suchard MA, Wu C-H, Xie D, Zhang C, 414 Stadler T, Drummond AJ. 2019. BEAST 2.5: An advanced software platform for Bayesian 415 evolutionary analysis. PLOS Computational Biology 15(4):e1006650.

416 Bradley DC, Ormerod JS. 2001. Community persistence among streams invertebrates tracks the 417 North Atlantic Oscillation. Journal of Animal Ecology 70:987-996.

418 Brower AVZ. 1994. Rapid morphological radiation and convergence among races of the 419 butterfly Heliconius erato inferred from patterns of mitochondrial DNA evolution. Proceedings 420 of the National Academy of Sciences of the United States of America 91(14):6491-6495. 421 Butler MJ, Hobbs HH. 1982. Drift upstream movement of invertebrates in a springbrook 422 community ecosystem. Hydrobiologia 89:153-159.

423 Casquet J, Thebaud C, Gillespie RG. 2012. Chelex without boiling, a rapid and easy technique to 424 obtain stable amplifiable DNA from small amounts of ethanol-stored spiders. Molecular Ecology 425 Resources 12(1):136-141.

426 Copilaș-Ciocianu D, Rutová T, Pařil P, Petrusek A. 2017. Epigean gammarids survived millions 427 of years of severe climatic fluctuations in high latitude refugia throughout the Western 428 Carpathians. Molecular Phylogenetics and Evolution 112:218-229 DOI:

429 10.1016/j.ympev.2017.04.027.

430 Copilaş-Ciocianu D, Zimţa A-A, Grabowski M, Petrusek A. 2018. Survival in northern 431 microrefugia in an endemic Carpathian gammarid (Crustacea: Amphipoda). Zoologica Scripta 432 47(3): 357-372 DOI: 10.1111/zsc.12285.

433 Cushing CE, Wolf EG. 1984. Primary production in Rattlesnake Springs, a cold desert spring434 stream. Hydrobiologia 114:229-236.

435 Čiamporová-Zat'ovičová Z, Čiampor JrF. 2017. Alpine lakes and ponds-a promising source of 436 high genetic diversity in metapopulations of aquatic insects. Inland Waters 7:109-117.

437 Dabkowski J, Frodlová J, Hájek M, Hájková P, Petr L, Fiorillo D, Dudová L, Horsák M. 2019. A 438 complete Holocene climate and environment record for the Western Carpathians (Slovakia) 439 derived from a tufa deposit. The Holocene 29(3): 493-504 DOI: 10.1177/0959683618816443.

440 Davis J, Pavlova A, Thompson R, Sunnucks P. 2013. Evolutionary refugia and ecological 441 refugees: key concepts for conserving Australian arid zone freshwater biodiversity under climate 442 change. Global Change Biology 19:1970-1984. 
443 Edgar RC. 2004. MUSCLE: multiple sequence alignment with high accuracy and high

444 throughput. Nucleic Acids Research 32:1792-1797.

445 Engelhardt C, Haase P, Pauls SU. 2011. From the Western Alps across Central Europe:

446 postglacial recolonisation of the tufa stream specialist Rhyacophila pubescens (Insecta,

447 Trichoptera). Frontiers in Zoology 8(10) DOI: 10.1186/1742-9994-8-10.

448 Excoffier L, Lischer HE. 2010. Arlequin suite ver 3.5: a new series of programs to perform

449 population genetics analyses under Linux and Windows. Molecular Ecology Resources 10:564-

450567.

451 Finn DS, Theobald DM, Black WC, Poff NL. 2006. Spatial population genetic structure and

452 limited dispersal in a Rocky Mountain alpine stream insect. Molecular Ecology 15:3553-3566.

453 Folmer O, Black M, Hoeh W, Lutz R, Vrijenhoek R. 1994. DNA primers for amplification of

454 mitochondrial cytochrome c oxidase subunit I from diverse metazoan invertebrates. Molecular

455 marine biology and biotechnology 3(5):294-299.

456 Frankham R. 2005. Genetics and extinction. Biological Conservation 126:131-140.

457 Frost S. 1971. Evaluation of kicking technique for sampling stream bottom fauna. Canadian

458 Journal of Zoology 49:161-173.

459 Fu YX, Li WH. 1993. Statistical tests of neutrality of mutations. Genetics 14:693-709.

$460 \mathrm{Fu} \mathrm{YX.1997.} \mathrm{Statistical} \mathrm{tests} \mathrm{of} \mathrm{neutrality} \mathrm{of} \mathrm{mutations} \mathrm{against} \mathrm{population} \mathrm{growth,} \mathrm{hitchhiking}$

461 and background selection. Genetics 147(2):915-925.

462 García-Criado F, Fernández-Aláez C, Fernández-Aláez M. 1999. Environmental variables

463 influencing the distribution of Hydraenidae and Elmidae assemblages (Coleoptera) in a

464 moderately-polluted river basin in north-western Spain. European Journal of Entomology 96:37-

46544.

466 Gibert J. 1991. Groundwater systems their boundaries: Conceptual framework prospects in

467 groundwater ecology. Verhandlungen des Internationalen Verein Limnologie 24:1605-1608.

468 Glazier DS, Gooch JL. 1987. Macroinvertebrate assemblages in Pennsylvania (U.S.A.) springs.

469 Hydrobiologia 150:33-43.

470 Gooch JL, Glazier DS. 1991. Temporal spatial patterns in mid-Appalachian springs. The

471 Memoirs of the Entomological Society of Canada 155:29-49.

472 Haubrock PJ, Kvifte GM, Langguth H, Wagner R. 2017. Glacial and postglacial species

473 divergence and dispersal of European trickle midges (Diptera: Thaumaleidae). Arthropod

474 Systematics \& Phylogeny 75(3):523-534.

475 Hewitt GM. 1999. Post-glacial re-colonization of European biota. Biological Journal of the

476 Linnean Society 68:87-112.

477 Hoffsten P-O. 2003. Effects of an extraordinarily harsh winter on macroinvertebrates and fish in

478 boreal streams. Archiv für Hydrobiologie 157: 505-523.

479 Illies J, Botosaneanu L. 1963. Problèmes et méthodes de la classification et de la zonation

480 écologique des eaux courantes, considérées surtout du point de vue faunistique. Mitteilungen der

481 Internationalen Vereinigung für Limnologie 12:1-57. 
482 Jamřichová E, Potůčková A, Horsák M. 2014. Landscape history, calcareous fen development 483 historical events in the Slovak Eastern Carpathians. Vegetation History Archaeobotany 23:497484513.

485 Jamřichová E, Petr L, Jiménez-Alfaro B. 2017. Pollen-inferred millennial changes in landscape 486 patterns at a major biogeographical interface within Europe. Journal of Biogeography 44:23864872397.

488 Jäch MA. 1992. 42.a Familie: Elmidae. In: Lhose GA, Lucht WH, ed. Die Käfer Mitteleuropeas. 489 Krefeld, Goecke \& Evers 13, 69-82.

490 Jedlička L, Kúdela M, Szemes T, Celec P. 2012. Population genetic structure of Simulium 491 degrangei (Diptera: Simuliidae) from Western Carpathians. Biologia 67:777-787 DOI: 492 10.2478/s11756-012-0057-2.

493 Johnson JA, Tingay RE, Culver M, Hailer F, Clarke ML, Mindell DP. 2009. Long-term survival 494 despite low genetic diversity in the critically endangered Madagascar fish-eagle. Molecular 495 Ecology 18:54-63.

496 Juřičková L, Pokorný P, Hošek J, Horáčková J, Květoň J, Zahajská P, Jansová A, Ložek V. 497 2017: Early postglacial recolonisation, refugial dynamics the origin of a major biodiversity 498 hotspot. A case study from the Malá Fatra mountains, Western Carpathians, Slovakia. The 499 Holocene 28(4):583-594 DOI: 10.1177/0959683617735592.

500 Kondracki J. 1989. Karpaty, 2nd edn. Warszawa: Wydawnictwa Szkolne i Pedagogiczne.

501 Kotlík P, Deffontaine V, Mascheretti S, Zima J, Michaux, JR, Searle JB. 2006. A northern 502 glacial refugium for bank voles (Clethrionomys glareolus). Proceedings of the National 503 Academy of Sciences of the United States of America 103:14860-14864 DOI:

504 10.1073/pnas.0603237103.

505 Kumar S, Stecher G, Tamura K. 2016. MEGA7: molecular evolutionary genetics analysis 506 version 7.0 for bigger datasets. Molecular Biology and Evolution 33:1870-1874.

507 Lehrian S, Pauls SU, Haase P. 2009. Contrasting patterns of population structure in the montane 508 caddisflies Hydropsyche tenuis and Drusus discolor in the Central European highlands.

509 Freshwater Biology 54:283-295.

510 Leigh JW, Bryant D. 2015. popart: full-feature software for haplotype network construction.

511 Methods in Ecology and Evolution 6:1110-1116.

512 Lewin I, Szoszkiewicz K, Jusik S, Ławniczak AE. 2015. Influence of selected environmental

513 factors on macroinvertebrates in mountain streams. Open Life Sciences 10:99-111.

514 Librado P, Rozas J. 2009. DnaSP v5: a software for comprehensive analysis of DNA

515 polymorphism data. Bioinformatics 25(11):1451-1452.

516 Lindner L, Dzierzek J, Marciniak B, Nitychoruk J. 2003. Outline of Quaternary glaciations in the

517 Tatra Mts.: their development, age limits. Geological Quarterly 47:269-280.

518 Magri D, Fineschi S, Bellarosa R, Buonamici A, Sebastiani F, Schirone B, Simeone MC,

519 Vendramin GG. 2006. A new scenario for the Quaternary history of European beech

520 populations: palaeobotanical evidence genetic consequences. New Phytologist 171:199-221. 
521 Maitland PS. 1967. The ecology of four species of Elminthidae in a Scottish river. Archiv für 522 Hydrobiologie 63:104-122.

523 Malicky H. 1983. Chorological patterns and biome types of European Trichoptera and other 524 freshwater insects. Archiv für Hydrobiologie 96:223-244.

525 Malicky H. 2000. Arealdynamik und Biomgrundtypen am Beispiel der Köcherfliegen 526 (Trichoptera). Entomologica Basiliensia 22:235-259.

527 Malicky H. 2006. Mitteleuropäische (extra-mediterrane) Arealkerne des Dinodal am Beispiel 528 von Köcherfliegen (Trichoptera). Beiträge zur Entomologie 56(2):347-359.

529 Mamos T, Wattier R, Majda A, Sket B, Grabowski M. 2014. Morphological vs. molecular 530 delineation of taxa across montane regions in Europe: the case study of Gammarus balcanicus 531 Schäferna, 1922 (Crustacea: Amphipoda). Journal of Zoological Systematics and Evolutionary 532 Research 52:237-248 DOI: 10.1111/jzs.12062.

533 Mamos T, Wattier R, Burzýnski A, Grabowski M. 2016. The legacy of a vanished sea: a high

534 level of diversification within a European freshwater amphipod species complex driven by 15

535 My of Paratethys regression. Molecular Ecology 25:795-810.

536 Mantel N. 1967. The detection of disease clustering and a generalized regression approach.

537 Cancer Research 27:209-220.

538 Meyer JL, Strayer DL, Wallace JB, Eggert SL, Helfman GS, Leonard NEL. 2007. The 539 contribution of headwater streams to biodiversity in river networks. Journal of the American 540 Water Resources Association 43:86-103.

541 Miller MP. 2005 Alleles In Space (AIS): Computer software for the joint analysis of 542 interindividual spatial and genetic information. Journal of Heredity 96:722-724 DOI:

$54310.1093 /$ jhered/esi119.

544 Minshall GW, Winger PV. 1968. The Effect of Reduction in Stream Flow on Invertebrate Drift. 545 Ecology 49:580-582.

546 Moog O, Jäch MA. 1995. Teil IIIC Längenzonale Verteilung nach biozöntalischen Regionen,

547 Coleoptera. In: Moog O, ed. Fauna Aquatica Austriaca, Bundesministerium für Land- und

548 Forstwirtschaft. Wien.

549 Mráz P, Ronikier M. 2016. Biogeography of the Carpathians: evolutionary spatial facets of 550 biodiversity. Biological Journal of the Linnean Society 119:528-559.

551 Neumann K, Michaux JR, Maak S, Jansman HA, Kayser A, Mundt G, Gattermann R. 2005.

552 Genetic spatial structure of European common hamsters (Cricetus cricetus)--a result of repeated 553 range expansion and demographic bottlenecks. Molecular Ecology 14:1473-1483 DOI:

554 10.1111/j.1365-294X.2005.02519.x.

555 Odum EP. 1971. Fundamentals of Ecology, Third Edition. Philadelphia: W.B. Saunders 556 company.

557 Orendt C. 2000. The chironomid communities of woodland springs and spring brooks, severely

558 endangered and impacted ecosystems in a lowland region of eastern Germany (Diptera:

559 Chironomidae). Journal of Insect Conservation 4:79-91. 
560 Pauls SU, Lumbsch HT, Haase P. 2006. Phylogeography of the montane caddisfly Drusus

561 discolor: evidence for multiple refugia and periglacial survival. Molecular Ecology 15(8):2153-

5622169.

563 Pinceel J, Jordaens K, Pfenninger M, Backeljau T. 2005. Rangewide phylogeography of a

564 terrestrial slug in Europe: evidence for Alpine refugia rapid colonization after the Pleistocene

565 glaciations. Molecular ecology 14:1133-1150.

566 Pringle CM, Naiman RJ, Bretschko G, Karr JR, Oswood MW, Webster JR, Welcomme RL,

567 Winterbourne MJ. 1988 Patch dynamics in lotic systems: the stream as a mosaic. J. North

568 American Benthological Society 7:503-524.

569 Rambaut A, Drummond AJ, Xie D, Baele G, Suchard MA. 2018. Posterior summarisation in

570 Bayesian phylogenetics using Tracer 1.7. Systematic Biology syy032 DOI:

571 10.1093/sysbio/syy032.

572 Ricklefs RE. 2007. Estimating diversification rates from phylogenetic information. Trends in

573 Ecology \& Evolution 22:601-10.

574 RStudio Team. 2020. RStudio: Integrated Development for R. RStudio, PBC, Boston, MA URL

575 http://www.rstudio.com/.

576 Schmitt T. 2007. Molecular biogeography of Europe: Pleistocene cycles and postglacial trends.

577 Frontiers in Zoology 4:11.

578 Spielman D, Brook BW, Frankham R. 2004. Most species are not driven to extinction before

579 genetic factors impact them. Proceedings of the National Academy of Sciences of the United

580 States of America 101:15261-15264.

581 Stadler T. 2011. Mammalian phylogeny reveals recent diversification rate shifts. Proceedings of

582 the National Academy of Sciences 108:6187-92.

583 Šípošová D, Čiamporová-Zatovičová Z, Čiampor JrF, 2017. Development of microsatellite loci

584 for two Agabus diving beetle species from the pooled DNA and testing their utility in mountain 585 lake populations. Limnologica 67:7-19.

586 Tajima F. 1989. The effect of change in population size on DNA polymorphism. Genetics 587 123(3):597-601.

588 Theissinger K, Bálint M, Feldheim KA, Haase P, Johannesen J, Laube I, Pauls SU. 2012. Glacial 589 survival and post-glacial recolonization of an arctic-alpine freshwater insect (Arcynopteryx

590 dichroa, Plecoptera, Perlodidae) in Europe. Journal of Biogeography 40:236-248.

591 Thorup J, Lindegaard C. 1977. Studies on Danish springs. Folia Limnol Scandanavica 17:7-15.

592 Ujvárosi L, Bálint M, Schmitt T, Mészáros N, Ujvárosi T, Popescu O. 2010. Divergence and

593 speciation in the Carpathians area: patterns of morphological and genetic diversity of the crane

594 fly Pedicia occulta (Diptera: Pediciidae). Journal of the North American Benthological Society

595 29(3):1075-1088.

596 Wielstra B, Babik W, Arntzen JW. 2015. The crested newt Triturus cristatus recolonized

597 temperate Eurasia from an extra-Mediterranean glacial refugium. Biological Journal of the

598 Linnean Society 114:574-587. 
599 Więźlak WW. 1986. Klucze do oznaczania owadów Polski, XIX, Chrząszcze - Coleoptera, 48, 60049 Parnidae, Limniidae, Psephenidae. Warszawa.

601 Wilcock HR, Bruford MW, Nichols RA, Hildrew AG. 2007. Landscape, habitat characteristics 602 the genetic population structure of two caddisflies. Freshwater Biology 52:1907-1929.

603 Wood PJ, Gunn J, Smith H, Abas-Kutty A. 2005. Flow permanence and macroinvertebrate 604 community diversity within groundwater dominated headwater streams and springs.

605 Hydrobiologia 545:55-64.

606 Vörös J, Mikulíček P, Major Á, Recuero E, Arntzen JW. 2016. Phylogeographic analysis reveals 607 northerly refugia for the riverine amphibian Triturus dobrogicus (Caudata: Salamandridae).

608 Biological Journal of the Linnean Society 119: 974-991 DOI: 10.1111/bij.12866. 


\section{Table $\mathbf{1}$ (on next page)}

Analysis of molecular variance (AMOVA) calculated from 273 COI mtDNA sequences of Elmis aenea and $245 \mathrm{COI}$ mtDNA sequences of Limnius perrisi from studied springs and streams in the W Carpathians.

(Subunits = geomorphological subunits. The subpopulation is defined as individuals of one sampling site, Tab. S1). 
E. aenea

\begin{tabular}{l|l|l|l|l|l|l}
\hline Source of variation & $\mathrm{df}^{1}$ & SS $^{2}$ & Variance components $\%$ of variation & $F$ value & $p$-value
\end{tabular}

\begin{tabular}{l|c|c|c|c|c|}
\hline Among subunits & 10 & 5.704 & 0.00206 & 1.02 & $F_{\text {CT }}=0.010>0.352$
\end{tabular}

\begin{tabular}{l|l|l|l|l|l|l|l|l} 
Among subpopulations within subunits 36 & 19.768 & 0.07080 & 34.99 & $F_{\text {SC }}=0.353>0.000$
\end{tabular}

Within subpopulations

23029.784

0.12950

$64 \quad \mathrm{~F}_{\mathrm{ST}}=0.360<0.000$

\section{L. perrisi}

Source of variation

\begin{tabular}{|l|l|l|l|l}
\hline df $^{1}$ & SS $^{2}$ & Variance components $\%$ of variation & $F$ value & $p$-value \\
\hline
\end{tabular}

\begin{tabular}{l|l|l|l|}
\hline Among subunits & 12 & 0.657
\end{tabular}

Among subpopulations within subunits $29 \mid 2.145$

Within subpopulations

1928.117

-0.00148
0.00602
0.04227

$-3.16 \quad F_{C T}=0.010>0.335$

$12.86 \quad F_{\text {SC }}=0.125>0.097$

df $^{1}$ Degree of freedom, $\mathbf{S S}^{2}$ Sum of squares

2

3

4 


\section{Table 2 (on next page)}

Values of neutrality tests (Fu's Fs, Tajima's D, Fu and Li's D test with p-values for Elmis aenea and Limnius perrisi mtDNA COI sequences. 


\begin{tabular}{l|c|c|c}
\hline Species & Fu's Fs test (p-value) & Tajima's $\boldsymbol{D}$ test (p-value) & Fu and Li's $\boldsymbol{D}$ test (p-value) \\
\hline Elmis aenea & $-17.331(0.000)$ & $-2.047(0.001)$ & $-3.323(<0.02)$ \\
Limnius perrisi & $-14.064(0.000)$ & $-2.004(0.002)$ & $-3.320(<0.02)$ \\
\hline
\end{tabular}

1

Peer] reviewing PDF | (2020:05:49199:2:1:NEW 3 Sep 2020) 


\section{Figure 1}

Maps of the studied area and sampling sites.

(A) Map of the studied area within the Carpathian Arc and (B) the 73 sampling sites (36 springs and 37 streams) divided into eight geomorphological units represented by different fill colors.(C) The altitude range of both elmid species. The boxplots show the distribution of the altitude above sea level for Elmis aenea and Limnius perrisi. The boxes represent the interquartile distances (IQD), while the centre lines through each box show the medians. The dot indicates outliers and the whiskers extend to the extreme values of the data, calculated as $\pm 1.5 \times$ IQD from the median. ANOVA analysis supported the dependence of species presence on altitude $(P<0.05)$. Abbreviations: Slovakia (SK), Hungary $(H)$, Ukraine (UA), Poland (PL), Czech Republic (CZ) and Austria (AU).

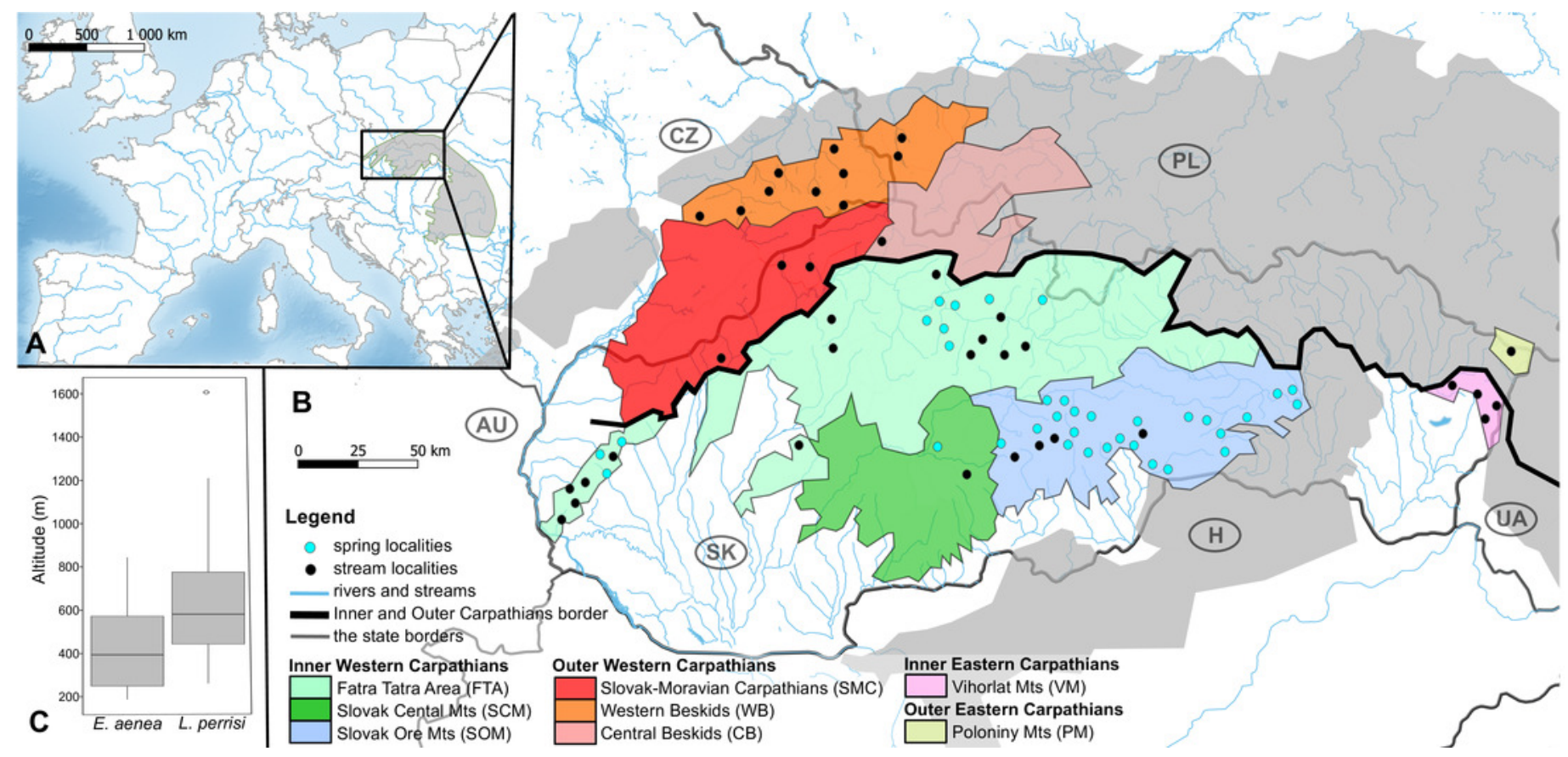




\section{Figure 2}

Elmis aenea sampling sites with mtDNA (COI) haplotype distribution and haplotype network.

(A) Investigated springs (31) and streams (16) with 13 mtDNA haplotypes distribution. Haplotypes are colours follow the Haplotype legend. Geomorphological units are represented by different fill colors according to the Legend. (B) Median-Joining network showing the relationships among haplotypes Ea1 - Ea20 (including available haplotypes outside W Carpathians). Sequences from Romania (12 sequences), Bulgaria (9 sequences), Finland (2 sequences), Germany (15 sequences) and France (1 sequence) are used for suggesting possible phylogenetic relationships and haplotype distribution of the W Carpathian haplotypes in the broader context . Circle fill patterns follow the Legend. Mutational steps are indicated with bars, small black dots represent undetected haplotypes. 


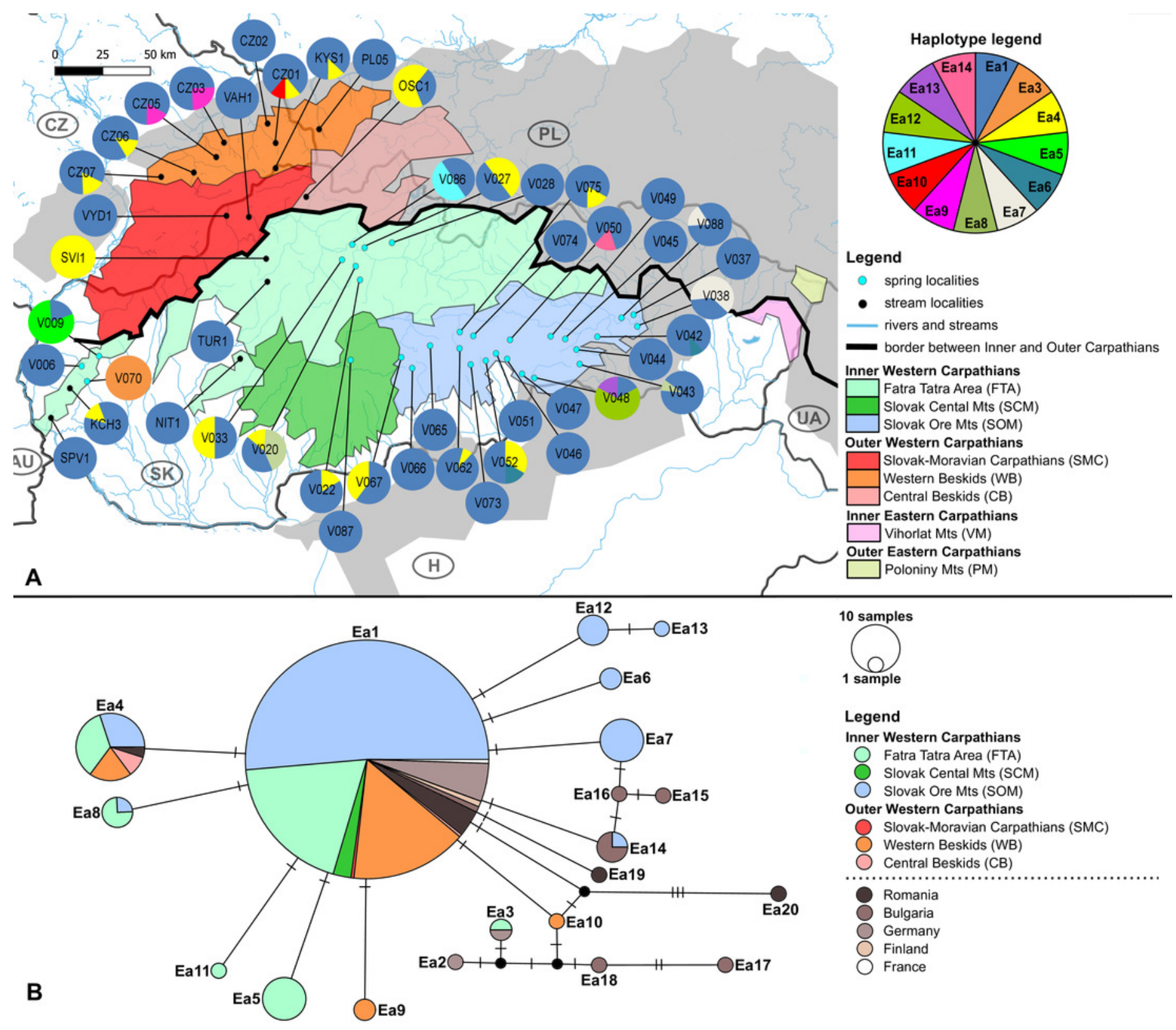




\section{Figure 3}

Limnius perrisi sampling sites with mtDNA (COI) haplotype distribution and haplotype network.

(A) Investigated springs (8) and streams (35) of L. perrisi with 7 mtDNA haplotypes distribution. Haplotypes are colours follow the Haplotype legend. Geomorphological units are represented by different fill colors according to the Legend. (B) Median-Joining network showing the relationships among haplotypes Lp1 - Lp13. Sequences from Romania (16 sequences), Bulgaria (2 sequences) and Germany (6 sequences) are used for suggesting the possible phylogenetic relationships and haplotype distribution of the W Carpathian haplotypes in the broader context. Circle fill patterns follow the Legend. Mutational steps are indicated with bars, small black dots represent undetected haplotypes. 


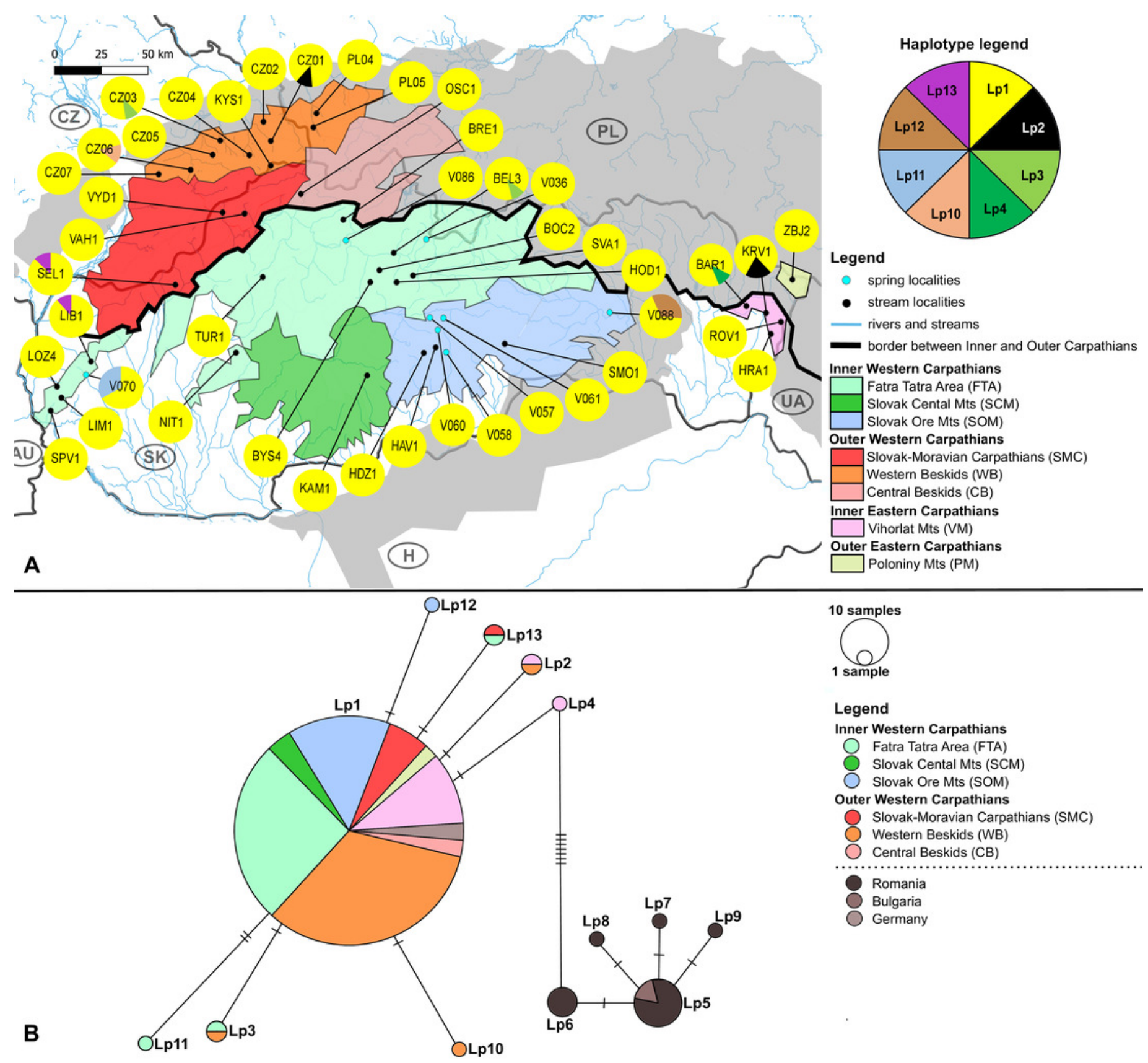


Figure 4

Comparison of molecular diversity indices between Elmis aenea and Limnius perrisi populations in Western Carpathians.

Box plots show (A) the haplotype diversity, (B) nucleotide diversity, (C) number of polymorphic sites and (D) average number of nucleotide differences. The statistical significance was computed with the Wilcoxon signed rank test for paired data ( $p$-value: above each box plot).

A

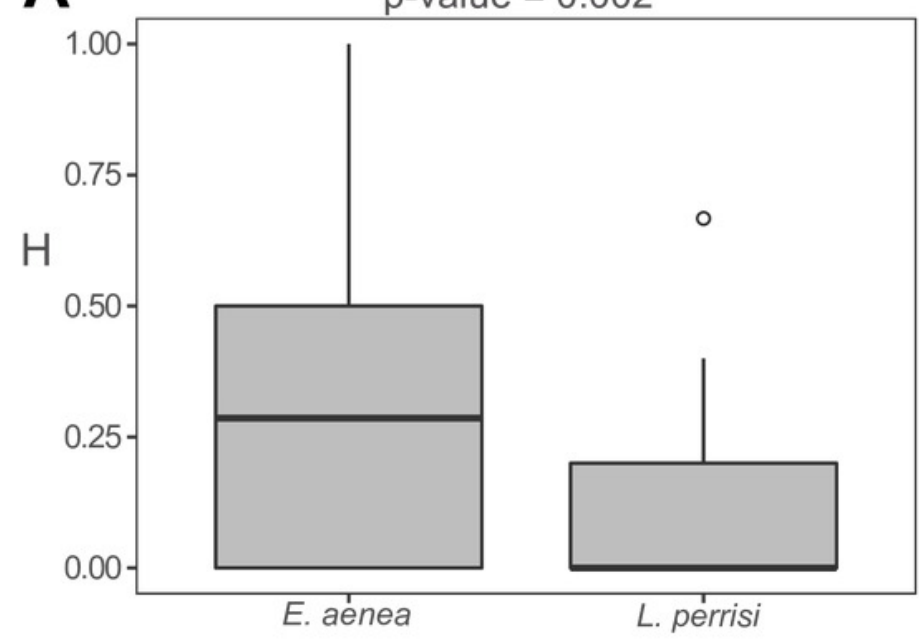

C

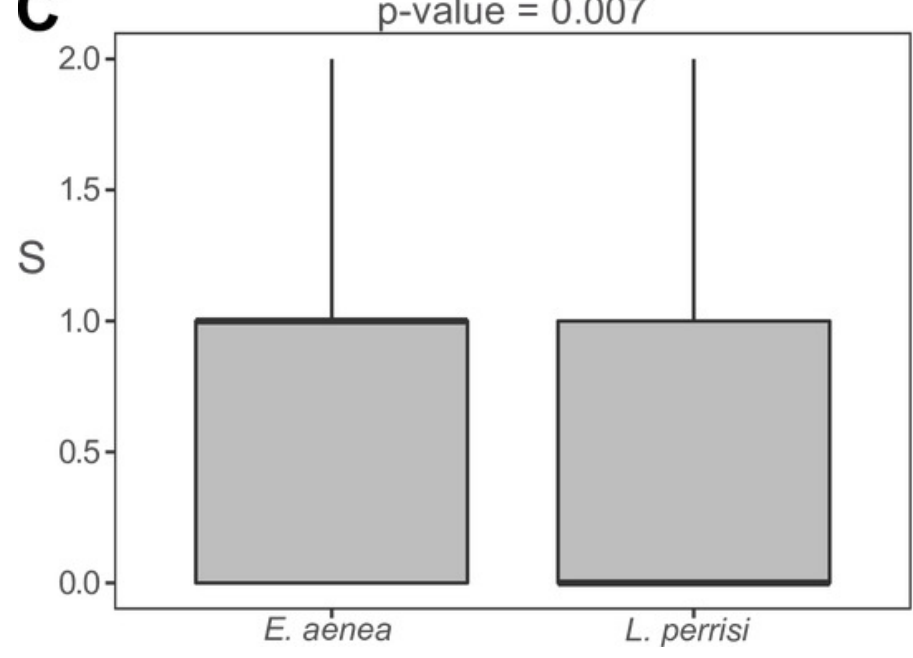

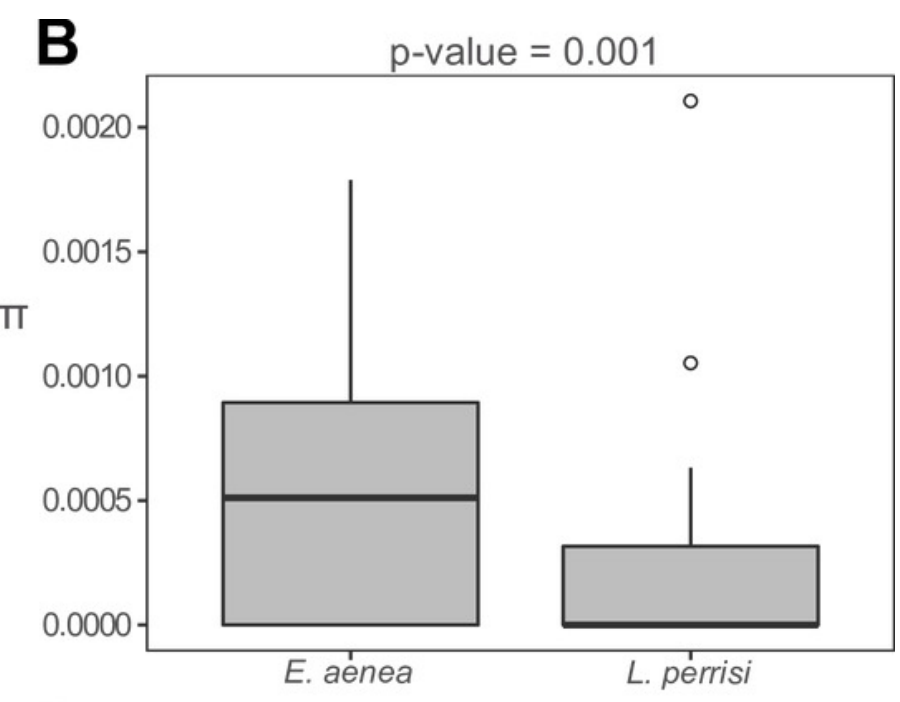

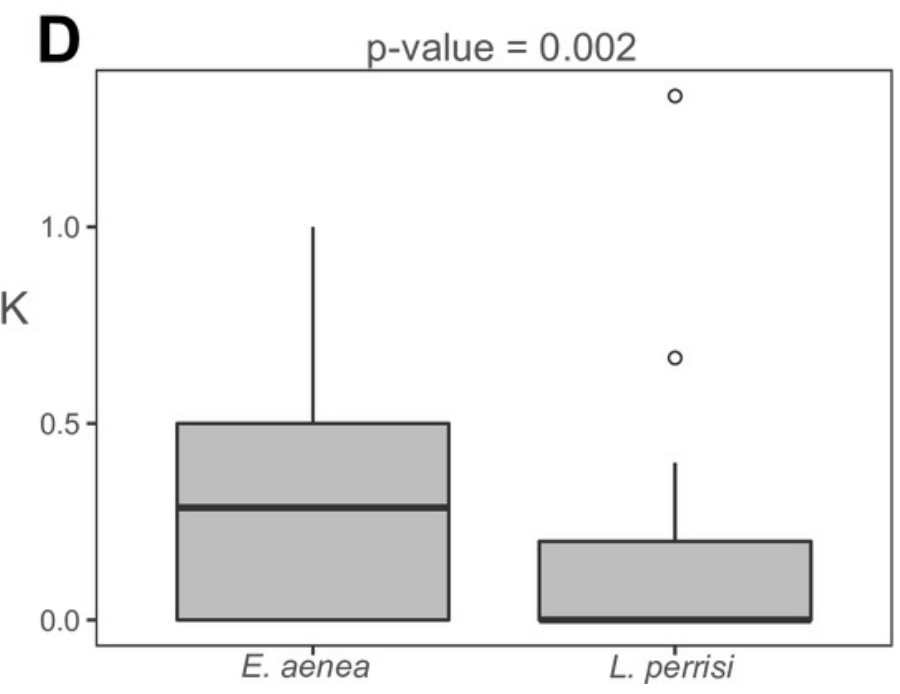




\section{Figure 5}

Heat map of pairwise $\mathrm{F}_{\mathrm{ST}}$ values among the studied sites (subpopulations) of (A) Elmis aenea and (B) Limnius perrisi in the W Carpathians.

Darker shades of blue rectangles indicate higher values of $\mathrm{F}_{\mathrm{ST}}$ (as displayed on the bar right of the heat map). White dots indicate $F_{S T} p$-values significantly different from zero $(P<0.05)$. The spring localities are distinguished by the blue color of the font. 

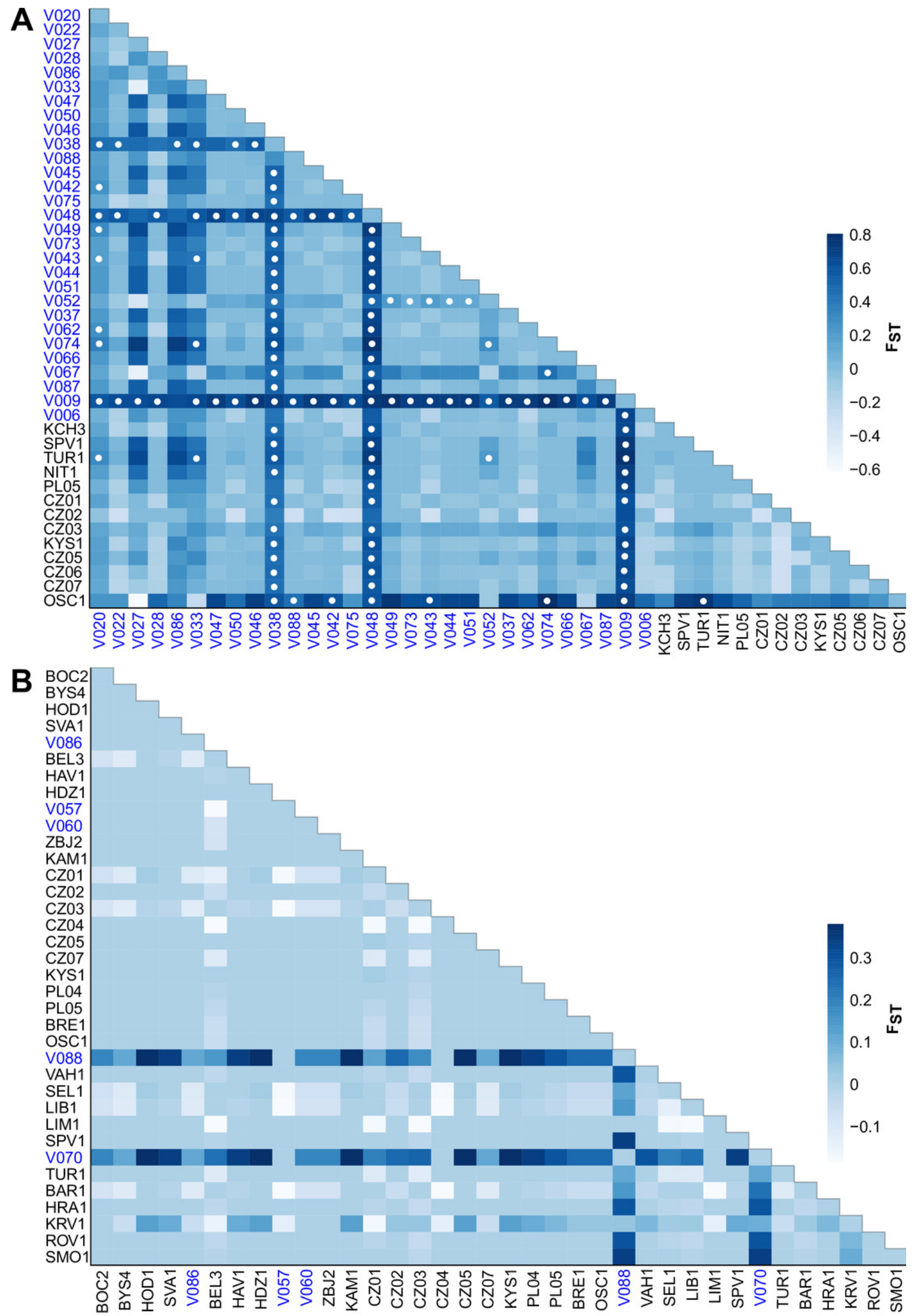


\section{Figure 6}

Mismatch distribution analysis of (A, B) Elmis aenea and (C, D) Limnius perrisi of the W Carpathian populations based on mtDNA.

Each plot shows the number ( $Y$ axis) of pairwise nucleotide site differences ( $X$ axis) among sequences for each species. The fit to the demographic expansion model is evaluated by the SSD and the $r$. The solid black line corresponds to the observed frequency of pairwise differences, the dotted red line represents the pattern expected under a model of sudden demographic expansion. The blue lines are the upper and lower boundaries of the $95 \%$ confidence interval.
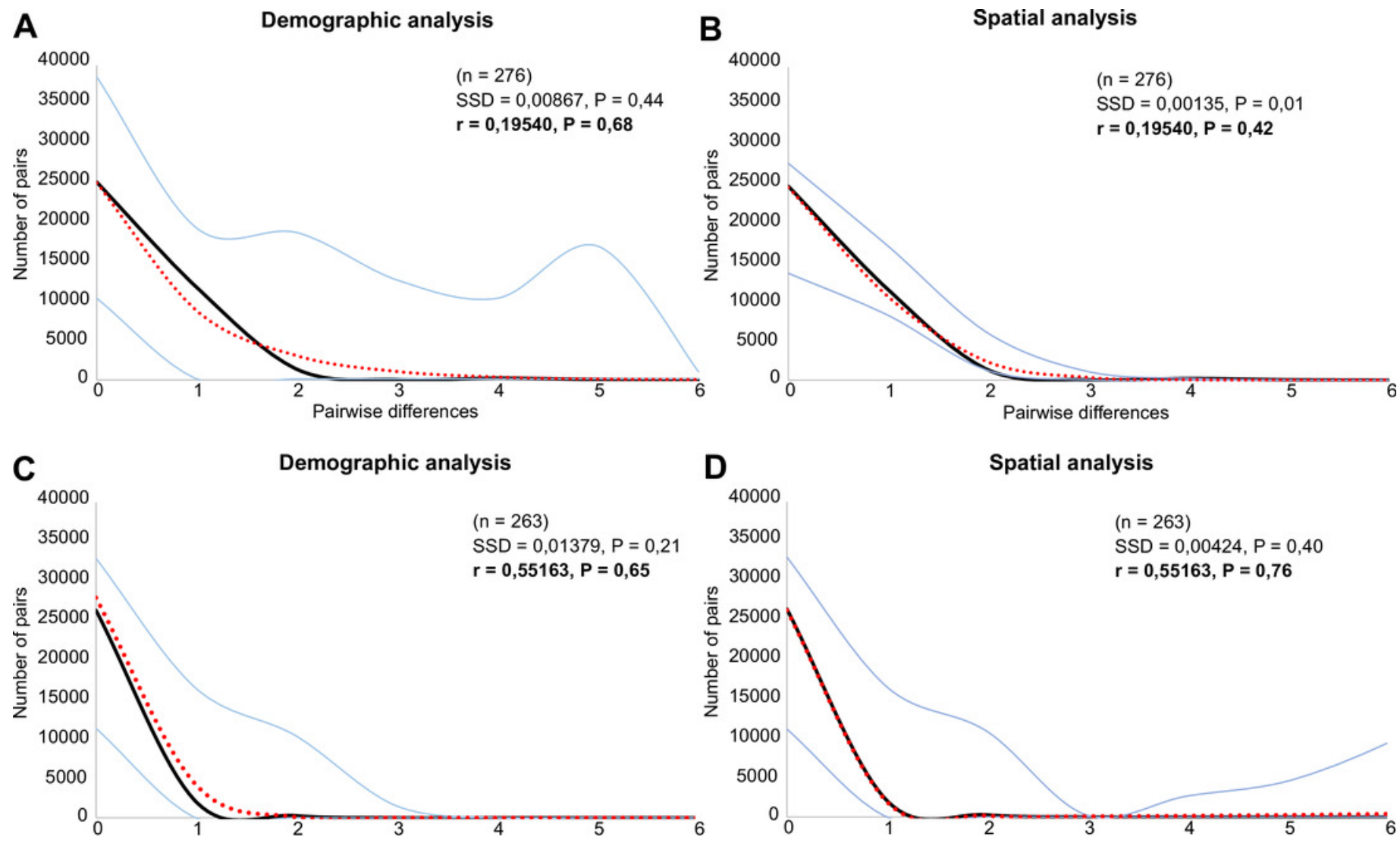


\section{Figure 7}

Extended Bayesian skyline plot based on mtDNA sequences of (A) Elmis aenea and (B) Limnius perrisi from investigated springs and streams of the W Carpathians, reconstructing the population size history using an evolutionary rate 0.0115 substit

The $\mathrm{x}$-axis is depicted on a scale of thousands of years (Kya), while $\mathrm{Y}$-axis corresponds to the mean effective population size. The dotted line represents the mean, while grey-shaded areas encompass $95 \%$ highest posterior density (HPD). 

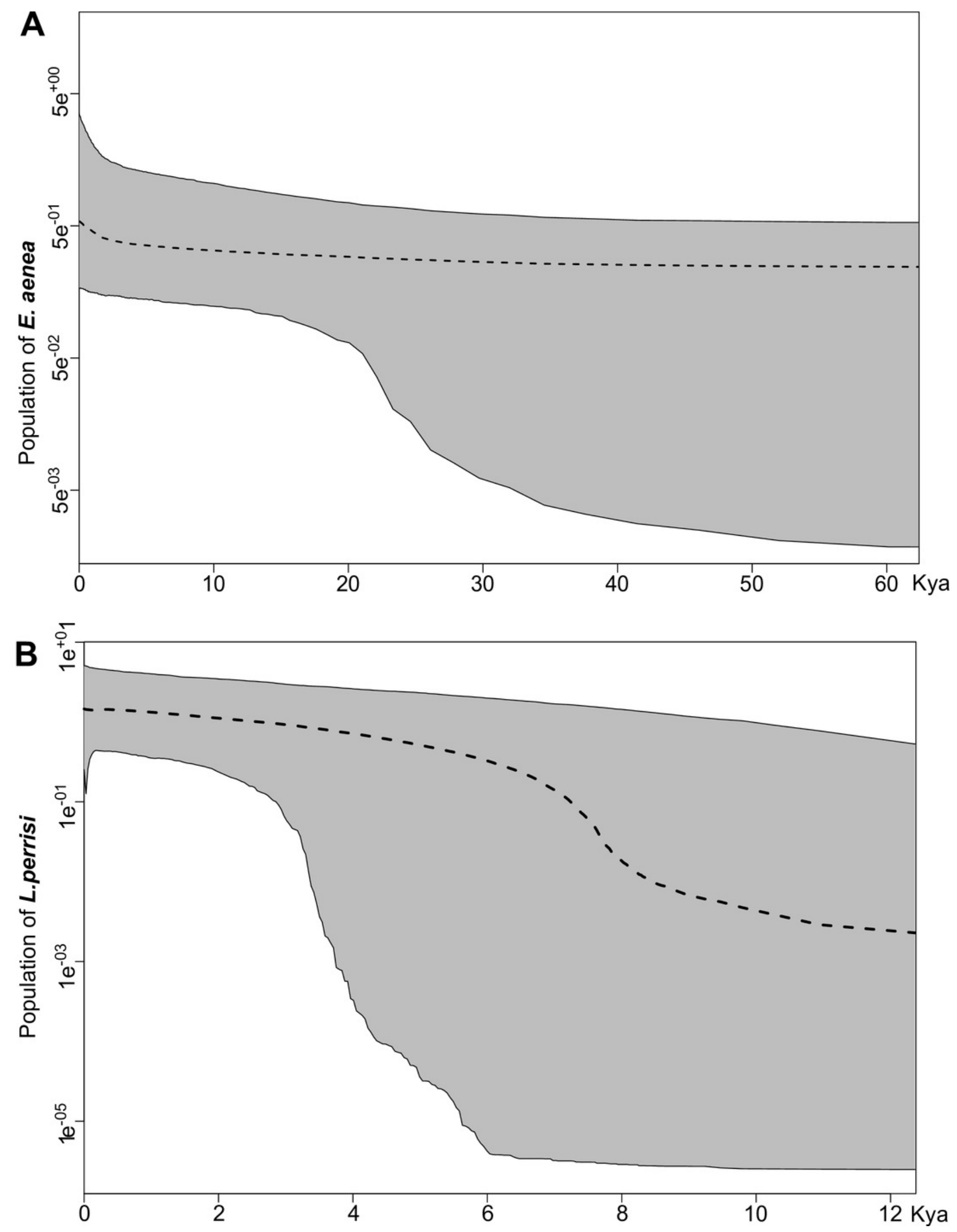

Peer] reviewing PDF | (2020:05:49199:2:1:NEW 3 Sep 2020) 